\title{
"Faz de conta que as crianças já cresceram": o processo de transição da Educação Infantil para o Ensino Fundamental
}

\author{
Adriana Zampieri Martinati \\ Pontifícia Universidade Católica de Campinas - Campinas - SP \\ Maria Silvia Pinto de Moura Librandi da Rocha \\ Pontifícia Universidade Católica de Campinas- Campinas - SP
}

\begin{abstract}
Resumo
O objetivo desta pesquisa foi analisar a transição da Educação Infantil (EI) para o Ensino Fundamental (EF) da perspectiva de crianças e professoras. O trabalho de campo foi realizado em duas fases: a primeira com uma turma de El; a segunda com uma turma de EF, na qual quatro das dez crianças acompanhadas na El foram matriculadas. Os procedimentos utilizados foram: observação do cotidiano escolar, entrevistas com as professoras e as crianças, análise documental e questionário com os pais. Os resultados indicaram poucos cuidados com a transição em ambas as instituições; à desarticulação e descontinuidade do trabalho pedagógico, as crianças respondem deformas diversas: ajustam suas condutas às exigências do novo contexto escolar, burlam-nas, cobram o cumprimento das promessas de tempo para brincar; algumas crianças externalizam sofrimento psíquico, ao qual as professoras reagem timidamente. Por meio de revisão bibliográfica, evidenciou-se a recorrência dos problemas encontrados nesta pesquisa, o que nos leva a reafirmar a importância de reflexões sobre as articulações entre a El e o EF, à luz da Teoria Histórico-Cultural e indicar a necessidade de debates sobre qual é o projeto brasileiro para a infância.
\end{abstract}

Palavras-chave: Ensino Fundamental; Educação Infantil; escola.

\section{"Pretend you've grown up": the transition process from Childhood Education to Elementary School}

\begin{abstract}
This research aimed to analyze the transition from Childhood Education (Educação Infantil - El) to Elementary School (Ensino Fundamental - EF) from the teachers' and the children's perspective. The fieldwork was conducted in two phases: the first with a group of El; the second with a group of $E F$, in which 4 of the 10 children followed in IE were enrolled. The procedures used were as follows: observation of the school day-by-day; interviews with the teachers and the children; documental analysis and questionnaire for the parents. The results indicated a lack of care regarding the transition. To the disarticulation and lack of continuity in the pedagogical work, children respond according to several tendencies: they adjust their behavior to the rules of the new school context, break them, ask to keep their playtime promises; some children externalize a psychic suffering, which the teachers react to in a shy manner. Based on the bibliographical review, it was possible to compare these results to other researches on the new EF, showing the recurrence of the issues found in our work. Therefore, the importance of discussing of articulation between El and EF is reaffirmed from a Historicalcultural theory point of view, which indicates the need for debating on what our project for childhood really is.
\end{abstract}

Keywords: Elementary school; early childhood education; school.

\section{"Se hace de cuenta que los niños ya han crecido": el proceso de transición de la Educación Infantil para la Enseñanza Fundamental}

\section{Resumen}

El objetivo de esta investigación fue analizar la transición de la Educación Infantil (EI) para la Enseñanza Fundamental (EF) de la perspectiva de niños y profesoras. El trabajo de campo fue realizado en dos fases: la primera con un grupo de El; la segunda con un grupo de EF, en la cual cuatro de los diez niños acompañados en la El fueron matriculadas. Los procedimientos utilizados fueron: observación del cotidiano escolar, entrevistas con las profesoras y los niños, análisis documental y cuestionario con los padres. Los resultados indicaron pocos cuidados con la transición en ambas instituciones; a la desarticulación y discontinuidad del trabajo pedagógico, los niños responden de formas diversas: ajustan sus conductas a las exigencias del nuevo contexto escolar, se burlan, cobran el cumplimiento de las promesas de tempo para jugar; algunos niños externalizan sufrimiento psíquico, al cual las profesoras reaccionan tímidamente. Por medio de revisión bibliográfica, se evidenció la recurrencia de los problemas encontrados en esta investigación, lo que nos lleva a reafirmar la importancia de reflexiones sobre las articulaciones entre la El y el EF, a la luz de la Teoría Histórico-Cultural e indicar la necesidad de debates sobre cuál es el proyecto brasileño para la infancia.

Palabras clave: Enseñanza fundamental; educación infantil; escuela. 


\section{Introdução}

A Lei $n^{\circ} 11.274(2006)$ instituiu o Ensino Fundamental de nove anos (EF), ampliando a sua duração através da antecipação da idade de matrícula das crianças nas escolas, que, a partir de então, deve ocorrer aos seis anos. Fato relativamente recente na educação brasileira, o novo EF requer mudanças organizacionais, estruturais, curriculares e de gestão em todos esses âmbitos, ao mesmo tempo em que novas questões são colocadas em pauta, revigoram-se temas bastante antigos no campo educacional. Este é o caso dos cuidados a serem tomados no processo de ingresso das crianças em suas novas escolas, aspecto destacado já há mais de 15 anos pelo Referencial Curricular Nacional para a Educação Infantil (Brasil, 1998):

A passagem da educação infantil para o ensino fundamental representa um marco significativo para a criança podendo criar ansiedades e inseguranças. O professor da educação infantil deve considerar esse fato desde o início do ano, estando disponível e atento para as questões e atitudes que as crianças possam manifestar. Tais preocupações podem ser aproveitadas para a realização de projetos que envolvam visitas a escolas de ensino fundamental; entrevistas com professores e alunos; programar um dia de permanência em uma classe de primeira série. É interessante fazer um ritual de despedida, marcando para as crianças este momento de passagem com um evento significativo. Essas ações ajudam a desenvolver uma disposição positiva frente às futuras mudanças demonstrando que, apesar das perdas, há também crescimento (Ministério da Educação e do Desporto, \& Secretaria de Educação Fundamental, 1998, p.84).

Este processo também é enfatizado nos documentos do Ministério da Educação publicados com a finalidade de orientar a implantação do novo EF. Os excertos a seguir ilustram esta questão:

Os processos educativos precisam ser adequados à faixa etária das crianças ingressantes para que a transição da Educação Infantil para o Ensino Fundamental aconteça sem rupturas traumáticas para elas (Ministério da Educação [MEC], 2004a, p.2).

É necessário que o sistema escolar esteja atento às situações envolvidas no ingresso da criança no EF, seja ela oriunda diretamente da família, seja da pré-escola, a fim de manter os laços sociais e afetivos e as condições de aprendizagem que Ihe darão segurança e confiança. Continuidade e ampliação - em vez de ruptura e negação do contexto socioafetivo e de aprendizagem anterior - garantem à criança de seis anos que ingressa no EF o ambiente acolhedor para enfrentar os desafios da nova etapa (MEC, 2004b, p.20).

É necessário assegurar que a transição da Educação Infantil para o Ensino Fundamental ocorra da forma mais natural possível, não provocando nas crianças rupturas e impactos negativos no seu processo de escolarização (Brasil, 2004b, p.22).

Apesar de ser um tema antigo, o processo de transição e seus impactos na vida das crianças é ainda escassamente estudado na literatura científica brasileira. Realizamos duas pesquisas bibliográficas, concomitantemente à pesquisa de campo. Na primeira (Rocha, Martinati, \& Santos, 2012), buscamos trabalhos publicados na Biblioteca Digital Brasileira de Teses e Dissertações (BDBTD) sobre o EF de 9 anos, com um recorte temporal de 2006 a 2011 e utilizando os descritores "ensino fundamental de nove anos" e "escola de nove anos". Compusemos nosso corpus com os trabalhos que elegessem o tema de maneira nuclear e relacionado à criança de seis anos; 26 trabalhos foram analisados em profundidade. Desses, apenas dois (7,69\%) ocuparam-se da transição da El para o EF (Neves, 2010; Motta, 2010). Na segunda pesquisa bibliográfica, buscamos trabalhos no mesmo banco de dados que tratassem do processo de ingresso em instituições escolares. Para tal, utilizamos o descritor "adaptação escolar", localizando 244 pesquisas. Dessas, apenas três abordavam o tema, sendo um referente ao ingresso na creche (Pantalena, 2010) e dois referentes à transição da El para o EF (Pizato, 2010; Santos, 2006).

Essa lacuna, em nossa perspectiva, ratifica a necessidade de maior aprofundamento sobre o assunto; a isto nos propomos neste artigo, a partir da formulação das seguintes questões: como tem se constituído a transição da El para o EF de nove anos? As proposições e os alertas que destacamos nos documentos repercutem nas práticas construídas nas unidades escolares? Buscamos respondera essas perguntas fundamentando-nos no material empírico produzido pela pesquisa de campo, analisado à luz da Psicologia Histórico-cultural, destacando-se seus aportes sobre o desenvolvimento humano, a centralidade do conceito de mediação e a importância do ingresso na escola. Exploraremos mais detidamente estes pontos teóricos a seguir.

\section{O desenvolvimento infantil e o ingresso na escola, na perspectiva Histórico-cultural}

Assim como em outros modelos da Psicologia, na abordagem Histórico-cultural encontramos esforços para a sistematização das mudanças que ocorrem ao longo do ciclo vital, ou seja, esforços de periodização do desenvolvimento humano; porém, aqui, os períodos são demarcados por atividades culturalmente situadas e não por características intrínsecas dos sujeitos, como ocorre em vertentes psicológicas naturalistas. Sendo assim, os períodos possíveis são determinados pelo meio, ou melhor, por aquilo que Vigotski (1996) chamou de situação social do desenvolvimento, definindo-a como

[...] o ponto de partida para todas as mudanças dinâmicas que se produzem no desenvolvimento durante o período de cada idade. Determina plenamente e por inteiro as formas e a 
trajetória que permitem à criança adquirir novas propriedades da personalidade, já que a realidade social é a verdadeira fonte de desenvolvimento, a possibilidade de que o social se transforme em individual. Portanto, a primeira questão que devemos resolver ao estudar a dinâmica de alguma idade, é esclarecer a situação social do desenvolvimento. (p.264).

São as situações sociais, portanto, que vão conduzir o curso de transformações pelas quais todo sujeito passa e a entrada das crianças na escola constitui-se numa situação social de especial relevância. Em vários trabalhos de A. R. Leontiev e D. B. Elkonin (por exemplo, Leontiev, 2001 e Elkonin, 1998) o ingresso na escola é explorado a partir do conceito de atividade. Os referidos autores argumentam que cada estágio do desenvolvimento é marcado por uma atividade principal, definindo-a como "[...] a atividade cujo desenvolvimento governa as mudanças mais importantes nos processos psíquicos e nos traços psicológicos da personalidade da criança, em certo estágio de seu desenvolvimento." (Leontiev, 2001, p.65). A atividade principal está relacionada, especialmente, com aspectos qualitativos: não é considerada necessariamente atividade principal aquela deque os sujeitos mais se ocupam, mas a que promove as mais importantes mudanças em suas personalidades.

No modelo teórico em foco, o ingresso na escola constitui um momento de passagem de um período de desenvolvimento para outro, promovendo-se o deslocamento da atividade principal que marca o período pré-escolar - a brincadeira (mais especificamente, os jogos de faz-de-conta) - para as atividades de estudo. O início da vida escolar é, portanto, um marco no desenvolvimento psicológico. Porém, é importante lembrar que, conforme assume Vigotski, a vivência da criança, a forma pela qual ela toma consciência e se relaciona com certo acontecimento, pode ser bastante variável e "uma ocorrência qualquer no meio ou uma situação qualquer influenciará a criança de formas diferentes, dependendo de como [...] compreende seu sentido e significado" (Vinha, \& Welcman, 2010, p. 688). Assim, o ingresso na escola e a assunção do estudo ao estatuto de atividade principal podem ter efeitos diferentes para cada sujeito. Considerando-se que a produção de sentidos e a compreensão de significados não se realizam de maneira individual e isolada das relações sociais, podemos afirmar que a variabilidade das vivências é condicionada por características da própria criança e pelas mediações que as pessoas que a cercam realizam.

Embora a teoria Histórico-cultural não seja mencionada nos trechos dos documentos que apresentamos no início deste artigo, podemos dizer que as orientações alinham-se com a tese geral de que as mediações fazem diferença nos modos como as crianças vivenciam a transição. Nestas orientações, podemos deduzir dois eixos de trabalho: (i) a construção de situações de diálogo, a partir das quais cada professor mostre-se "disponível e atento para as questões e atitudes que as crianças possam manifestar" e (ii) o planejamento de estratégias intencionalmente voltadas para o tema, por exemplo, na El, "realizar projetos que envolvam visitas a escolas de ensino fundamental", "entrevistas com professores e alunos [das novas escolas]", "fazer um ritual de despedida"; no EF, "reorganizar a sua estrutura, as formas de gestão, os ambientes, os espaços, os tempos, os materiais, os conteúdos, as metodologias, os objetivos, o planejamento e a avaliação, de sorte que as crianças se sintam inseridas e acolhidas num ambiente prazeroso e propício à aprendizagem". Na organização desse cotidiano, destaca-se a importância da atividade lúdica para a construção de um percurso menos descontínuo para o desenvolvimento psicológico infantil.

Argumenta-se que, embora a alfabetização (importante e preponderante foco do trabalho pedagógico no EF) deva receber atenção sistemática nos currículos escolares, a constituição humana é mais ampla do que a aquisição de um conhecimento específico. Assim, afirma-se ser importante oferecer-Ihe atividades mais estruturadas de estudo e atividades lúdicas, tanto no ano final da Educação Infantil, quanto nos anos iniciais do Ensino Fundamental. Nos termos da teoria Histórico-cultural podemos dizer que se trata de criar as melhores condições possíveis para que a transição das atividades principais - das brincadeiras para o estudo - ocorra de forma gradual e cuidadosa.

\section{Método}

O objetivo da pesquisa foi analisar a transição da Educação Infantil para o Ensino Fundamental da perspectiva de crianças e professoras. Organizamos o trabalho de campo em duas fases:

- Fase I ( $2^{\circ}$ semestre de 2011): realizada com uma turma de uma Escola Municipal de Educação Infantil - EMEI, do município de Campinas (SP), composta por 15 crianças de 5 e 6 anos de idade e sua professora. Deste grupo, 10 crianças ingressariam no EF em 2012.

- Fase II (1 ${ }^{\circ}$ semestre de 2012): realizada junto a uma turma de $1^{\circ}$ ano de uma Escola Municipal de Ensino Fundamental (EMEF), próxima da EMEI; para esta turma foram encaminhadas cinco crianças do grupo acompanhado na El.

Os instrumentos usados foram: (i) questionário com os pais, para acessarmos informações sobre idade, profissão e nível de escolaridade; (ii) observação do cotidiano escolar, com registros em videofilmagens, no diário de campo e fotografias; (iii) entrevistas com as duas professoras; (iv) entrevistas com as crianças, com produção de desenhos, leitura e comentários de histórias a respeito do ingresso na escola, conversas sobre o tema e (v) análise documental dos projetos pedagógicos das duas escolas.

Buscamos utilizar diferentes instrumentos que privilegiassem várias formas de expressão das crianças, num esforço para acessar as significações produzidas por elas sobre o processo de transição escolar. Esta decisão decorreu 
do reconhecimento de que a pesquisa com esta faixa etária apresenta vários desafios, especialmente quando se propõe que discorram sobre temas (e não apenas se registra o que elas enunciam naturalmente); um deles é a necessidade de se manter um clima informal e de atenuar, no limite máximo possível, a hierarquia existente entre adultos e as crianças.

As entrevistas com as crianças foram grupais, em arranjos compostos por quatro crianças (em média), por considerarmos que, assim, elas se sentiriam mais à vontade para se expressarem, poderiam ouvir pontos de vista diferentes, abrindo maior leque de diálogos e interações, muito próximas das situações de seu cotidiano.

A seguir, apresentaremos os resultados de nosso trabalho.

\section{Resultados}

Optamos por organizar os resultados em torno dos dois eixos explicitados nas prescrições dos documentos: (i) o que fazem/dizem as professoras quanto ao processo de transição e (ii) adesão/resistências das crianças e (iii) professoras e crianças: sentimentos em foco.

\section{O que fazem/dizem as professoras}

A abordagem do tema "a nova escola" na EMEI ocorreu em dois dias durante o período de observação. No primeiro dia da pesquisa, em 7 de outubro de 2011, a professora Suelen ${ }^{1}$ menciona rapidamente a saída das crianças da El em futuro próximo, ao explicar para elas a presença da pesquisadora. O tema volta a ser focalizado apenas no dia 29 de novembro. A seguir, apresentamos estas situações.

\section{$07 / 10 / 2011$}

Professora Suelen: Então, deixa a pro conversar com vocês. A Adriana vai fazer uma pesquisa da faculdade que ela faz. Ela escolheu a El, que são vocês, para poder fazer essa pesquisa, porque depois alguns alunos daqui vão lá para a $1^{a}$ série, né, que é a escola de nove anos.

Luiz [olhando para a pesquisadora]: Não tô entendendo o que ela tá falando.

Professora Suelen: O que vai acontecer Luiz...Ela vai filmar, ela vai fazer umas fotos e ela vai ver o que tá acontecendo aqui na sala, como é o trabalho que é feito aqui. Certo? Então, vocês não se preocupem... Ela vai estar filmando, vai estar vendo vocês pintando, fazendo atividade, tudo o que a gente faz nessa sala ela vai estar olhando, porque ela está muito curiosa pra saber o que acontece aqui.

\section{$29 / 11 / 2011$}

Neste dia, em duas situações a transição foi novamente abordada. Primeiro, a professora Suelen diz para a

1 Todos os nomes dos participantes são fictícios. pesquisadora que a listagem indicando as escolas para as quais os alunos iriam já se encontrava afixada na escola. Essa informação foi dada em voz alta, de modo que as crianças puderam ouvi-la. Elas, entretanto, não fazem nenhuma pergunta, nem são convidadas a participar do diálogo.

Algum tempo depois, a pesquisadora pergunta à professora se a escola realiza festa de encerramento do ano letivo e/ou alguma atividade especial para a despedida das crianças da El. A professora diz:

Professora Suelen: A gente não queria fazer. [...] nós já fazemos a festa da família para valer por todas. Ficou combinado que era só festa da família.

Ou seja, a equipe pedagógica desta EMEI havia abolido festas comemorativas como dia das mães, dia dos pais etc. e optado por realizar apenas a festa da família, um evento realizado no mês de setembro, no qual mostram-se aos pais as atividades realizadas pelas crianças, com apresentações.

No mesmo dia, a coordenadora pedagógica da EMEI soube que a pesquisadora estava encerrando sua pesquisa de campo, mas que se houvesse festa de encerramento e/ou formatura voltaria;imediatamente, a coordenadora disse que haveria a festa.No final do dia, a pesquisadora comentou com a professora Suelen a incongruência das informações; esta explicou que quando a equipe decidiu realizar apenas a festa da família a coordenadora pedagógica estava afastada e, por isso,não sabia dessa decisão. Assim, muito provavelmente por influência da pergunta da pesquisadora, a festa de encerramento foi realizada às pressas, no dia 13 de dezembro de 2011; todas as turmas foram reunidas no pátio da escola, cada uma apresentou uma música, depois formou-se um coral das crianças, professoras e funcionários, acompanhadas por violões, tocados por duas professoras, a diretora e o segurança. No final, ofereceu-se suco e bolo aos pais. A diretora explicou que a festa comemorava o encerramento do ano; não houve qualquer menção à saída das crianças da EMEI e ingresso na EMEF e/ou qualquer ação que funcionasse como recurso para valorizar aquele momento importante nas suas vidas.

$\mathrm{Na}$ entrevista realizada com a professora Suelen, ao ser indagada sobre quais investimentos eram feitos na EMEI relativos à transição, ela respondeu que:

Professora Suelen: A única coisa que a gente faz é falar: "Ó, você... É seu último ano nessa escola. Você já vai pra outra escola. Lá vai ter diferença sim nas atividades". E eles... Mesmo os pais acabam falando: "Ah, lá [no EF] você vai aprender a ler e a escrever". É o que a gente escuta muito. Daí eu falo: "Lá vocês não vão ter a quantidade de brincadeiras que vocês têm aqui, vocês vão ter algo a mais". [...] É mais agora no final do ano, porque eles já sabem que vão pra outra escola. Mas não que a gente fique aguçando, para eles acabarem até sofrendo... Porque tem criança que é um pouco mais ansiosa [...]. Eu acho que eles estão assim... Meio que indiferentes [...].

Deste trecho destacamos três aspectos: na abordagem da transição focaliza-se o estreitamento das brincadeiras no futuro escolar, concomitante à valorização da 
alfabetização; a divisão de responsabilidades com os pais das crianças para informá-las sobre as mudanças iminentes, ao que parece executadas por escola e família em direção sintônica; o entendimento da professora de que falar mais sobre o assunto pode ter efeitos ruins sobre seus alunos, o que esclarece-nos melhor a predominância de silêncio.

$\mathrm{Na}$ EMEF, as ações para o ingresso das crianças restringiram-se ao encurtamento do período de permanência na escola nos dois primeiros dias, encerrando-se as aulas às 9h30min. No primeiro dia, ocorreu a apresentação das regras da escola para os pais/responsáveis e crianças, todos reunidos na sala de aula:

Professora Márcia [escreve na lousa "7 horas" e diz]: Aí vocês levantam, escovam os dentes. Faz xixi? [...]. Faço xixi, escovo os dentes. Então [na escola] eu só vou poder ir ao banheiro às 8 horas [escreve "8 horas"]. Antes disso eu posso ir ao banheiro?

Crianças: Não!

Após a explicação, a professora pergunta a seus alunos quais são seus nomes e os das escolas de El que frequentaram no ano anterior. Esta foi uma das poucas situações em que houve menção a experiências educacionais anteriores das crianças.

Professora Márcia: Tem recreio aqui? Tem um pouquinho de recreio. Não é como na escola de ensino infantil que tem bastante, né? E aqui também tem parque. Esse ano a gente tem um parque novo... Fica lá embaixo. Só que, por enquanto, tá ocupado [diz em voz baixa, para a pesquisadora: "Para variar"]. Tá cheio de carteira [carteiras estragadas foram empilhadas no parque à espera de remoção], mas eles vão tirar tudo para a gente poder usar. Nos primeiros dias eu gostaria de muita atenção: horarinho, nove e meia? Nove e vinte cinco eu [representando os adultos que virão buscar os alunos] estou no portão. Por quê? Porque a ansiedade da saída de ir embora, de não ver a mãe, traz essa expectativa. Alguém vai dormir na escola? Não tem tempo pra dormir não e nem vai almoçar na escola, porque não tem comida para todo mundo. [...]. Fiquem tranquilos: às vezes, a mamãe vem buscar de carro, às vezes, o trânsito lá está difícil, atrasa uns minutinhos. Mas a professora Márcia está aqui com vocês, combinado? É pra chorar? Não, mamãe já vem! Mas aí, a Professora Márcia vai pedir pras mamães no primeiro dia não atrasar, porque cria ansiedade e excitação. Então combinado? A mamãe vai chegar sempre cedo até a criança se sentir segura.

Quando questionamos a professora sobre o processo de transição ela explicou:

Professora Márcia: [...] houve essa preocupação de como fazer essa transição sem que haja ruptura da El para o EF [...] deveria sempre existir essa preocupação, inclusive uma integração maior dos professores da El com os professores do EF, principalmente com as professoras de $1^{\circ}$ ano.

Pesquisadora: Mas existe algo na prática? Ou por enquanto não?

Professora Márcia: Ainda não está acontecendo. [...] Eu busco as orientações, né? Busco conhecer a criança que vem da El, qual é a expectativa dessa criança, como é que ela vem, como é que ela espera [que seja o primeiro ano], a gente até faz brincadeiras pra resgatar isso das crianças. Eu vou trabalhando conforme as expectativas. [Além disso] a gente faz a avaliação diagnóstica. É uma avaliação, são atividades [que indicam] em que fase da alfabetização ela está, e aí a gente vai fazendo os agrupamentos e eu vou propiciando a essas crianças atividades diferenciadas.

Professora Márcia [dirigindo-se à pesquisadora]: Eles estavam acostumados na outra escola [...] Eu não consigo entender isso, Adriana. [...]. Eu acho que tem que respeitar, a criança tem que ter um espaço... Então é uma coisa que eu discordo, vou me aposentar e não vou abrir a cabeça desse povo.

Apesar das preocupações que a professora manifesta, seus investimentos concretos na direção de superar os problemas no processo de transição foram bem escassos. Existe preocupação com a falta de espaço para as crianças brincarem e com o que nomeou como "descaso do sistema de ensino", que integrou a criança de seis anos sem oferecer subsídios necessários aos professores que atuam com elas. Salientou problemas quanto ao mobiliário inadequado para as crianças, ressalvando que esta medida foi necessária, pois a sala do $1^{\circ}$ ano, no período vespertino, era ocupada por alunos de $9^{\circ}$ ano:

Professora Márcia [na reunião de pais]: Então, para os nossos de $1^{\circ}$ ano essa carteira é ruim [...] só que [traz] menos problemas para a criança do $1^{\circ}$ ano que para as do $9^{\circ}$ ano, porque as pernas são altas e a carteira [para crianças menores] não dá.

Subvertendo as regras sobre "como sentar corretamente", as crianças criaram formas de adaptação em relação ao mobiliário, ajoelhando-se nas carteiras, ficando em pé enquanto faziam suas tarefas, sentando em cima das próprias pernas para ficarem mais altas... Constantemente eram censuradas.

Professora Márcia: Senta direito Isabela. Nossa, eu vou ter que ensinar de novo como eu sento? Olha as crianças com as costinhas sem encostar! Isso pode dar dor nas costas depois.

\section{Adesões/resistências das crianças}

As entrevistas realizadas com as 10 crianças da EMEI evidenciam que elas assumem de modo bastante consistente que a nova escola é lugar de aprender a ler e a escrever e mostram-se dispostas a viverem esta nova experiência. Quando pedimos a elas que dissessem o que fariam se pudessem escolher entre ficar na El ou ir para o EF, todas as crianças disseram que preferiam ir para a nova escola. As razões que apresentam giram em torno das expectativas de que farão novos amigos, aprenderão mais e não apenas "coisas de bebezinhos", conforme disse Ingrid, uma das crianças. Quando foram questionadas sobre quem/o que escolheriam - caso pudessem fazer isso - para levar da $\mathrm{El}$ para o EF, $70 \%$ escolheriam um ou mais amigos e $60 \%$ o parquinho e os brinquedos. 
Apesar da adesão e valorização consensual sobre a importância do que aprenderiam na nova escola, ao longo dos dois primeiros meses de frequência na escola de EF, as quatro crianças que acompanhamos, incansavelmente, fizeram solicitações de oportunidades para brincarem. Rafael foi quem mais se empenhou neste campo.

06/02/12 - Durante a apresentação da professora de Educação Física

Rafael: Vai ter jogo aqui?

No fim da aula, antes de ir embora, Rafael questiona a professora Márcia se poderia brincar no parque, mas ela não responde.

07/02/12 - Durante a aula

Rafael: Professora Márcia, nós vamos brincar hoje no parquinho?

Professora Márcia: Sabe por que não dá pra ir ao parquinho ainda? Vocês olharam lá? Nós estamos com muito material da escola que está quebrado: mesinha, cadeira, armário. Pra poder receber vocês e a classe estar com a carteirinha boa, precisava levar o material [quebrado] lá pro parquinho. Quando tirarem o material lá do parquinho, aí nós podemos ir lá, porque agora tá muito cheio e não dá pra gente nem brincar lá. Mas a gente depois pode fazer uma brincadeira no pátio, na quadra, tá?

Rafael: Já tiraram as carteiras de lá?

Professora Márcia: Não tiraram as carteiras de lá.

Rafael: Ainda não?

Professora Márcia: Ainda não, tá?

Rafael faz cara de desapontado e após um tempo questiona novamente:

Rafael: Pode brincar um pouco, Professora Márcia?

Professora Márcia: Não podemos brincar. Nós podemos brincar aqui na sala?

Crianças: Não, lá fora.

Rafael: Só um pouquinho...

Professora Márcia: Mas não dá, o pessoal tá tomando lanche. Nós vamos combinar o dia do parque. Vocês entraram lá por baixo, viram lá um lugar que tinha um parquinho?

Rafael: Não vi.

Professora Márcia: Não viu o parquinho?Lá embaixo tem o parquinho. É super legal.

08/02/12 - Aula de Educação Física

Rafael: Hoje a gente vai no parquinho!

Professora Silvana: Não, porque na aula de Educação Física tem que mexer o corpo.

08/02/12 - Após o recreio

Rafael: $E$ brincar? [após a professora Márcia dizer aos alunos que não era para guardar o estojo, pois continuariam a ter aula após o recreio].

08/02/12 - Na realização da atividade

Rafael: Professora Márcia, nós vamos brincar hoje? [A professora não escuta ou ignora a pergunta de Rafael].

Como respostas a essas perguntas sobre as possibilidades de brincar, as crianças recebiam, na maior parte das vezes, negativas ou evasivas. Em razão disso, subvertiam a regra estabelecida de que no espaço da sala de aula não podiam brincar, constatada nas manifestações de episódios lúdicos de curtíssima duração. Foi assim que, durante o período de observação, estojos foram transformados em aviões, lápis em injeção, espadas e baquetas de bateria, tesouras transformadas em espadas, tubos de cola em telefone celular, microfone e em pino de boliche; pastas viraram violão, palitos para a Matemática viraram instrumento de examinar gargantas, sorvetes etc.; as crianças com seus corpos imitaram borboletas, a Barbie, robôs, gatinhos... Inúmeras operações de substituições de significados, típicas dos jogos de faz-de-conta foram registradas. Nem sempre a professora viu essas brincadeiras; quando isto ocorreu, repreendeu seus alunos:

Professora Márcia: Rodrigo, eu vou mudar os dois de lugar. Aqui não é horarinho de brincar agora. Horarinho de brincar, eu vou falar: "Agora é hora de brincar". Agora não é hora de brincar, agora é hora de prestar atenção que a gente tem que aprender bastante coisa diferente. É um pouquinho diferente da EMEI, CEMEI...

Professora Márcia: Bruno... É batuque? É escola de samba aqui? Barulho não [quando viu a criança batendo o lápis na carteira].

Professora Márcia: Vamos parar de brincar Rodrigo, com o lápis e a cola? Cola é brinquedo? [...] Essa cola, esse tubo aí é o que? É celular por acaso? Não! Vamos prestar atenção? Vamos?

\section{Professoras e crianças: sentimentos em foco}

Iniciamos este tópico retomando o que disse a professora Suelen sobre os receios que tem e que limitam suas iniciativas de conversar sobre a finalização da vida das crianças na EMEI e seu futuro ingresso na EMEF: "[...] não que a gente fique aguçando, para eles acabarem até sofrendo... Porque tem criança que é um pouco mais ansiosa [...]. Eu acho que eles estão assim... Meio que indiferentes [...]". A mesma estratégia adotada por Suelen de silenciar e fazer silenciar quando se trata da dimensão afetiva é identificada na forma como a Márcia conduz certas situações:

Professora Márcia: A Ana Júlia estudava no Estado, né, Ana Júlia? E agora ela veio pra gente. Lógico, quase um mês na outra escola, ela vai sentir. Ana Júlia, tá chorando por quê? Você quer sua mãe? Eu também quero a minha, como é que eu vou fazer? [...]. Vamos Ana Júlia, copia isso rapidinho, para de chorar. Choro não adianta, molha caderno, rasga a folha.

Outra criança da turma, Sônia, teve um comportamento inesperado. Nos primeiros dias de aula, sentou-se perto de suas amigas da EMEl e parecia tranquila. Após um mês de aula, a professora colocou-a sentada ao lado de Rafael (vindo da mesma EMEI) formando com ele uma dupla, nas carteiras agrupadas de duas em duas. Ao longo da jornada escolar Sônia estava abatida, parecia ansiosa, mordendo os lábios, mexendo as mãos constantemente e esfregando os olhos, para enxugar as lágrimas.

Rafael: Ela tá chorando. 
Professora Márcia: Ela não tá chorando. Se ela quiser chorar ela vai, mas eu já combinei com ela.

A professora Márcia relata que conversou com a mãe de Sônia sobre esses episódios de choro e ambas concluíram que ela passou a chorar "só para chamar atenção porque ela quer a mãe" e que a melhor estratégia a ser adotada seria ignorar este comportamento; o argumento usado para estas conclusões foi o de que no período de adaptação à EMEI,Sônia também tinha chorado, durante vários dias.

A informação de que estes sinais de sofrimento na adaptação já haviam ocorrido na trajetória da criança, de nosso ponto de vista, deveria ser tomada como um elemento a ser considerado no ingresso de Sônia na nova escola, de modo a evitar que a experiência de dor psíquica se repetisse ou para buscar atenuá-la. Merece ser destacado que a informação de que Sônia teve dificuldades no momento de ingresso na El só surge quando os problemas de ingresso na EF se explicitam.

Revendo as videogravações e analisando os momentos da primeira semana de aula e após um mês, verificamos que a mudança mais evidente na turma foi o início dos agrupamentos em sala de aula, que são um aspecto importante para a interação das crianças, mas que no caso de Sônia, talvez não tenha funcionado bem. Nas filmagens, é possível perceber que, apesar de sentar junto com o colega designado pela professora, Sônia não conversa com ele nenhuma vez; ou seja, os benefícios que se espera que a formação de duplas traga para as interações entre as crianças não se concretizam neste caso.

Analisando as respostas dadas pelas crianças nas entrevistas e na produção de desenhos na El e no EF, identificamos que Sônia foi a única que mudou de opinião sobre o que disse em 2011 (quando estava na El) e em 2012 (quando estava no primeiro ano do EF e já conhecia, concretamente, o cotidiano escolar).

\section{Em 2011}

21/11/11

Pesquisadora: Se pudesse escolher, o que você preferia: ficar na El ou ir para o EF?

Sônia: [Prefiro ir para] a escola nova. Porque lá eu vou ter amigos legais. Vou aprender a ler, vai aprender a escrever. Vou aprender matemática também.

[...] Eu acho que a minha nova escola vai ser bem legal! Eu acho que vai ter quadra, mas quadra mais legal!

\section{$23 / 11 / 11$}

Sônia (explicando o desenho que fez sobre a nova escola): [Sou eu] Entregando o caderno pra professora.

Pesquisadora: E o que você vai fazer com esse caderno?

Sônia: Fazer tarefa!

\section{Em 2012}

06/03/12

Pesquisadora: Se pudesse escolher, você preferia ficar nesta escola ou ficar na outra (EI)?

Sônia: [Preferia ter ficado] na outra escola.

Entrevistadora: Por quê?

Sônia: Porque é legal... Mas essa aqui também é legal.

Entrevistadora: Mas você gostava mais da outra escola?

Sônia: [silêncio] Mas estou me acostumando com essa...

$13 / 03 / 12$

A pesquisadora pediu que Sônia procurasse explicar o motivo dela ter chorado em alguns momentos e ela respondeu:

Sônia: Porque tem gente que me assusta, mas agora eu não estou mais com medo.

Pesquisadora: Quem assusta você?

Sônia: Tem menino, tem menina.

Pesquisadora: Tem muita gente, por isso fica assustada?

Sônia balança a cabeça concordando.

\section{Discussão}

Tomamos o caso de Sônia como de um problema que se faz presente em vários pontos do processo de transição: o silêncio e/ou as limitações nas possibilidades de diálogo entre os seus protagonistas (crianças e professoras).

De nossa perspectiva, a ausência de diálogo no caso específico desta criança repercute de forma dolorosa. Formulamos, então, as seguintes perguntas: se a professora Márcia soubesse, conversando com Sônia, que sua melhor amiga da EMEl estava na mesma classe, e colocasse-as para formarem uma dupla, ela teria se sentido mais tranquila? Novos arranjos nos agrupamentos poderiam aproximar Sônia de crianças que interagiriam com ela de modo a ajudá-la a não ficar tão angustiada?

Certamente são apenas hipóteses; porém, como sabemos, muitas vezes, pequenos detalhes podem ser interpretados pelas crianças como fatos muito importantes e podem se tornar decisivos nos modos como elas se ajustam ou não às situações sociais de suas vidas. O fato é que Sônia estava sofrendo e qualquer tentativa para atenuar seus sentimentos dolorosos deveria ser realizada. Intrigar-se com as ocorrências de choro, perguntar-se sobre o que poderia ter acontecido e sobre o que poderia ser feito para tentar superar esta situação, seria mais produtivo do que apenas considerar esta questão como uma característica da criança que o tempo se incumbirá de mudar..

As razões que levam Sônia a chorar se explicam, ao menos em parte, por situações concretas interpretadas por ela como ameaçadoras. A professora prefere não explorá- 
-las e, também baseada em fatos concretos (o choro no passado, a vinculação forte com a mãe), produz suas próprias interpretações; as interpretações de ambas não chegam a entrar em confronto já que não são explicitadas entre criança e professora. Não conversar sobre sentimentos foi típico nas relações que acompanhamos.

É importante notar que as duas professoras do nosso estudo não buscaram saber o que as crianças nos diziam sobre as suas vivências na El e no EF. Estavam cientes de que nas entrevistas em pequenos grupos, através da leitura, conversas e produção de desenhos, esses eram os temas focalizados; Suelen e Márcia, porém, apartaram-se dos conteúdos abordados por seus alunos ao longo do desenvolvimento da pesquisa. Não acessaram, portanto, os registros de que as crianças (i) nomeiam amigos, brinquedos e parque, ao indicarem o que gostariam de ter trazido da EMEI para a EMEF; (ii) respondem "brincar com os amigos" quando perguntamos do que mais sentem saudades, considerando o que faziam com os colegas na EMEI; neste último tópico, das 10 crianças entrevistadas na EMEl apenas uma responde que não sente saudades de nada. As mesmas respostas apareceram nos desenhos produzidos, permitindo-nos uma visão clara de quanto as relações entre pares e as brincadeiras seguem sendo importantes para a criança de 6 anos que está no EF.

Um último campo a ser comentado refere-se à ausência de diálogo entre as unidades de El e EF. Aqui é importante acrescentar que nos Projetos Pedagógicos analisados (da EMEI e da EMEF) não encontramos citações e/ou previsão de ações relativas à transição escolar. É certo que não haver registros sobre esta articulação não quer dizer que ela não ocorra. Porém, sabendo que os Projetos Pedagógicos são documentos-guia da vida das unidades escolares, a incorporação desse item traria menores chances de se perdê-lo de vista.

Considerando em conjunto o que pudemos ouvir e ver no cotidiano das unidades educacionais podemos dizer que está em jogo nas circunstâncias pelas quais se processa a transição da El para o EF o conceito de drama formulado por Vigotski. Conforme Delari (2011):

Em geral, a noção de "drama" em Vigotski varia entre duas acepções principais: (1) uma mais coloquial, por exemplo: "o desenvolvimento humano como drama (peça teatral) em vários atos"; e (2) outra mais específica, destacando numa ação "dramática" dois aspectos: 2.1 um ato de decisão humana sobre a condução de seu destino histórico; 2.2 o choque entre diferentes papéis que cada pessoa vivencia [perejivaet]. Estas peculiaridades constituem o caráter (in) tenso e dialeticamente conflituoso de se decidir socialmente por um caminho vital ou outro num dado contexto históricocultural - desde o mais corriqueiro até aquele no qual pode estar envolvida uma situação de vida ou morte - "ser ou não ser" (p.181, ênfase nossa).

No caso em foco, inegavelmente as crianças experimentam um choque entre diferentes papéis: aquele que elas aprenderam a desempenhar na El e o que se espera delas no EF. As diferenças radicais na forma de organização entre as duas instituições educacionais demandam a constituição de novos modos de funcionamento psicológico, novos modos de ser criança. $\mathrm{Na} \mathrm{El}$, a centralidade do trabalho pedagógico é a atividade lúdica, a rotina é bastante flexível e as crianças possuem mais liberdade e autonomia na realização das atividades. No EF, o foco é a alfabetização, realizada dentro de uma rotina rígida em que, na maior parte do tempo, as crianças devem ficar sentadas em sala de aula, obedecendo às regras e ao ritmo da escola. Nesse cenário, as crianças as crianças desempenham os dois papéis: o de alunos que brincam e estudam. Decorre disso o fato de as crianças agirem no cotidiano escolar segundo tendências diversas:ajustam suas condutas às exigências do novo contexto, burlam-nas, cobram da professora as promessas de tempo para brincar... Ou seja, têm consciência de que sua posição social mudou e estão dispostas a atender às novas exigências implicadas nessa mudança. Mas, não plenamente, já que, para elas, este novo papel não é excludente do anterior.

De sua parte, as professoras não dizem abertamente para as crianças que o tempo de brincar nos espaços escolares acabará/acabou. São ambíguas em seus enunciados, sugerindo que para a atividade de que seus alunos mais gostam ainda serão reservados alguns momentos no cotidiano escolar, embora bastante discretos. Mas, de fato, é muito difícil fazerem isso acontecer. As professoras reconhecem a importância das brincadeiras, mas na maior parte do tempo fazem de conta que as crianças já cresceram.

O estatuto de prestígio atribuído às aprendizagens escolares afeta a visão das crianças sobre a nova escola, levando-as a ajustarem-se bastante bem ao que é mais valorizado em nossa sociedade. As crianças querem mudar de escola, valorizam o acesso a novas aprendizagens, mas ao mesmo tempo, desejariam levar junto os símbolos indiscutíveis da El: elegem o parquinho e brinquedos como aquilo de que sentirão saudades quando forem para a outra escola. Insistentemente dão pistas, através de seus comportamentos e solicitações para que possam brincar, de que ainda são crianças para as quais a atividade lúdica é essencial.

O EF ampliado promoveu a antecipação do ingresso das crianças de seis anos nesse nível de ensino, trazendo para os profissionais da educação proposições de mudanças em relação às práticas pedagógicas, de modo a assegurar a construção de um bom contexto para a infância. Neste cenário, produziram-se documentos oficiais nos quais encontram-se alertas sobre a importância de se conhecer a criança de 6 anos e suas especificidades, no que diz respeito ao seu desenvolvimento psicológico, para atendê-las; dentre elas a necessidade de brincar é assumida como uma das mais importantes. Essas asserções, que podem até parecer simples e/ou óbvias, na realidade implicam em debates que se ocupem em responder: o que são as especificidades da criança de 6 anos?

$\mathrm{Na}$ perspectiva histórico-cultural, o desenvolvimento humano é compreendido como o processo de domínio 
progressivo das formas culturais de funcionamento psicológico, fruto das relações sociais; é, portanto, um fenômeno histórico e contextualizado dentro de cada cultura. Vygotsky (1996) destaca a formação de novos interesses e novas motivações nas crianças como aspecto fundamental na dinâmica do desenvolvimento, principalmente vinculada ao conceito de crise:

Desse ponto de vista, a essência de toda crise reside na reestruturação da vivência interior, reestruturação que se encontra na mudança do momento essencial que determina a relação da criança com o meio, isto é, na mudança de suas necessidades e motivações, que são os motores de seu comportamento (p. 397).

O conceito de crise é bastante complexo e, de nossa perspectiva, carece de maiores aprofundamentos na literatura científica. Há, inclusive, necessidade de tornar mais preciso o uso do termo e variações que constam nos textos dos autores fundadores do modelo teórico em foco. Por exemplo, se em Vygotski (1996) as crises são indicadas como parte constitutiva, produtiva e inescapável do desenvolvimento, conforme podemos ler no seguinte trecho "A idade escolar, como todas as idades, começa por uma etapa de crise ou virada, descrita pelos cientistas antes que as demais, como a crise dos sete anos" (p.366), em Leontiev (1978, p.296) o uso do termo crise ganha outros contornos:

\footnotetext{
Na realidade, estas crises não acompanham, inevitavelmente o desenvolvimento psíquico. O que é inevitável não são as crises, mas as rupturas, os saltos qualitativos no desenvolvimento. A crise, pelo contrário, é o sinal de uma ruptura, de um salto que não foi efectuado no devido tempo. Pode perfeitamente não haver crise se o desenvolvimento psíquico da criança se não efectuar espontaneamente, mas como um processo racionalmente conduzido de educação dirigida (p.296).
}

Os resultados de nossa pesquisa, principalmente quando colocados em interlocução com outros trabalhos que se dedicaram a estudar o tema do ingresso das crianças de 6 anos nas escolas (Rocha, \& cols, 20122; Motta, 2010; Neves, 2010; Pantalena, 2010; Pizato, 2010; Santos, 2006) permitem-nos enfatizar a importância de não se considerar as necessidades e motivações das crianças, sejam as de 6 anos sejam as de quaisquer outras idades como naturais. Em todos os trabalhos lidos, pudemos constatar que o ingresso nas escolas realizou-se como um processo de adaptação dos alunos às normas das instituições, durante o qual

2 Parte desta bibliografia já foi mencionada neste artigo por ocasião da apresentação da pesquisa bibliográfica que fizemos na Biblioteca Digital Brasileira de Teses e Dissertações (Rocha, \& cols, 2012); ou outros textos acrescentados foram sendo acessados por revisão bibliográfica que acompanhou todo o processo de investigação. algumas necessidades, motivações e/ou especificidades das crianças foram legitimadas - as de aprender a ler, escrever, calcular - e outras - as relacionadas a poderem brincar e poderem se sentir fisicamente confortáveis em suas salas de aula - foram desconsideradas. É difícil identificar precisamente os resultados dessa dinâmica no desenvolvimento psicológico, mas parece-nos legítimo hipotetizar, a partir da teoria Histórico-cultural, que ela tem/terá efeitos sobre as crianças e que pode significar um processo de crise (no sentido que Leontiev dá a este termo) que poderia/deveria ser evitado.

\section{Considerações finais}

Ao finalizar este artigo, é necessário reconhecer que boa parte das razões pelas quais a transição das crianças da El para o EF ocorre de forma pouco articulada e necessidades e motivações das crianças são desconsideradas extrapolam as possibilidades que as professoras têm de controle sobre o que podem fazer com seus alunos no cotidiano escolar: as condições materiais das escolas, as exigências dos exames de avaliação externa que lhes impõem a necessidade de trabalhar maciçamente com a alfabetização, as poucas condições que as secretarias de educação lhes dão para contato com as unidades de segmentos diferentes da rede, entre outras, impactam cotidianamente o trabalho docente.

Vale notar que essas exigências e problemas originam-se exatamente da mesma fonte na qual se produzem as prescrições para que haja mudanças nos currículos escolares, que práticas diversas sejam neles legitimadas e que o processo de ingresso das crianças nas novas escolas seja feito numa perspectiva de continuidade daquilo que viveram nas unidades de El: os órgãos em que se formulam as políticas públicas de Educação. Sendo assim, defrontamo-nos e, mais acirradamente, defrontam-se as professoras brasileiras com exigências muito difíceis de conciliar. Os antagonismos dessas exigências nos conduzem a perguntarmos sobre qual é, de fato, o projeto para a construção da infância ao qual as professoras têm que aderir.

\section{Referências}

Delari Jr., A. (2011). Sentidos do "drama" na perspectiva de Vigotski: um diálogo no limiar entre arte e psicologia. Psicologia em Estudo, 16(2), 181-197.

Elkonin, D. B. (1998). Psicologia do jogo (2aed). São Paulo: Martins Fontes.

Lei n. 11.274 (2006). Estabelece as diretrizes e bases da educação nacional, dispondo sobre a duração de 9 (nove) anos para o ensino fundamental, com matrícula obrigatória a partir dos 6 (seis) anos de idade. Diário Oficial da União, Brasília. 
Leontiev, A. N. (1978). O desenvolvimento do psiquismo. Lisboa: Horizonte.

Leontiev, A. N. (2001). Uma contribuição à teoria do desenvolvimento da psiqueinfantil. Em L. S. Vygotski, A. R. Luria, \& A. N. Leontiev (Orgs.), Linguagem, desenvolvimento e aprendizagem (pp.59-83). São Paulo: Ícone/Edusp.

Ministério da Educação e do Desporto. Secretaria de Educação Fundamental. (1998). Referencial Curricular para a Educação Infantil: Introdução. Brasília, DF: MEC/SEF.

Ministério da Educação (2004a). Ampliação do Ensino Fundamental para nove anos: $1^{\circ}$ relatório do programa. Brasília, DF: Secretaria de Educação Básica.

Ministério da Educação (2004b). Ensino Fundamental de nove anos: orientações gerais. Brasília, DF: Secretaria de Educação Básica.

Ministério da Educação (2006). Secretaria de Educação Básica. Ensino Fundamental de Nove Anos: orientações para a Inclusão da Criança de Seis Anos de Idade. Brasília, DF: Secretaria de Educação Básica.

Motta, F. M. N. (2010). De crianças a alunos: transformações sociais na passagem da educação infantil para o ensino fundamental. Tese de Doutorado em Educação. Pontifícia Universidade Católica do Rio de Janeiro, Rio de Janeiro - RJ.

Neves, V. F. A. (2010). Tensões contemporâneas no processo de passagem da Educação Infantil para o Ensino Fundamental: um estudo de caso. Tese de Doutorado em Educação, Universidade Federal de Minas Gerais, Belo Horizonte - MG.

Pantalena, E. S. (2010). O ingresso da criança na creche e os vínculos iniciais. Dissertação de Mestrado em Educação. Faculdade de Educação da Universidade de São Paulo, São Paulo-SP.

Pizato, E. C. G. (2010). Um estudo longitudinal de trajetórias de desempenho escolar. Tese de Doutorado em Psicologia. Faculdade de Filosofia, Ciências e Letras de Ribeirão Preto/USP, Ribeirão Preto-SP.

Rocha, M. S. P. M. L. da, Martinati, A. Z., \& Santos, M. S. P. dos. (2012). Ensino Fundamental de nove anos: contribuições para a construção de um panorama nacional de implantação e implementação. Pesquisaeduca. 4(8), 296-316.

Santos, K. C. dos. (2006). Autonomia da criança: transição da educação infantil para o ensino fundamental, conforme as prescrições oficiais. Dissertação de Mestrado em Educação: História, Política, Sociedade, Pontifícia Universidade Católica de São Paulo, São Paulo-SP.

Vinha, M. P. \& Welcman, M. (2010). Quarta aula: a questão do meio na pedologia, Lev Semionovich Vigotski. Psicologia USP, 21(4), 681-701.

Vygotski, L. S. (1996). Obras escogidas IV. Madrid: Visor. 


\section{Sobre as autoras}

Adriana Zampieri Martinati (azmartinati@gmail.com)

Pontifícia Universidade Católica de Campinas

Mestre em Educação (PUCC). Membro do Grupo de Pesquisa Formação e Trabalho Docente na Linha de Pesquisa "Formação de Professores e Práticas Pedagógicas" (PUCC). Tutora da Faculdade de Ciências e Tecnologia da Universidade Estadual Paulista (FCT/UNESP).

Maria Silvia Pinto de Moura Librandi da Rocha (msilvia@puc-campinas.edu.br)

Pontifícia Universidade Católica de Campinas

Doutora em Educação (Unicamp). Professora permanente do Programa de Pós-Graduação em Educação da PUC-Campinas. Líder do Grupo de Pesquisa Formação e Trabalho Docente na Linha de Pesquisa «Formação de Professores e Práticas Pedagógicas» (PUCC).

Este artigo é parcialmente derivado da dissertação de mestrado "Faz de conta que eu cresci: o processo de transição da Educação Infantil para o Ensino Fundamental" (Adriana Zampieri Martinati), financiada pela CAPES. A coleta de dados foi efetuada nas mesmas instituições educacionais na dissertação e no artigo. 
